\title{
Vertical Structure of Midlatitude Analysis and Forecast Errors
}

\author{
GREGORY J. HAKIM \\ University of Washington, Seattle, Washington
}

(Manuscript received 3 February 2004, in final form 2 September 2004)

\begin{abstract}
The dominant vertical structures for analysis and forecast errors are estimated in midlatitudes using a small ensemble of operational analyses. Errors for fixed locations in the central North Pacific and eastern North America are selected for comparing errors in regions with relatively low and high observation density, respectively. Results for these fixed locations are compared with results for zonal wavenumber 9 , which provides a representative sample of baroclinic waves. This study focuses on deviations from the ensemble mean for meridional wind and temperature at $40^{\circ} \mathrm{N}$; these quantities are chosen for simplicity and because they capture dynamical and thermodynamical aspects of midlatitude baroclinic waves.

Results for the meridional wind show that analysis and forecast errors share the same dominant vertical structure as the analyses. This structure peaks near the tropopause and decays smoothly toward small values in the middle and lower troposphere. The dominant vertical structure for analysis errors exhibits upshear tilt and peaks just below the tropopause, suggesting an asymmetry in errors of the tropopause location, with a bias toward greater errors for downward tropopause displacements. The dominant vertical structure for temperature analysis errors is distinctly different from temperature analyses. Analysis errors have a sharp peak in the lower troposphere, with a secondary structure near the tropopause, whereas forecast errors and analyses show a dipole straddling the tropopause and smooth vertical structure, consistent with potential vorticity anomalies due to variance in tropopause position.

Linear regression of forecast errors onto analysis errors for the western North Pacific is used to assess the nonseparable zonal-height structure of errors and their propagation. Analysis errors near the tropopause rapidly develop into a spreading wave packet, with a group speed that matches the mean zonal wind speed of $31 \mathrm{~m} \mathrm{~s}^{-1}$. A complementary calculation for the regression of 24-h forecast errors onto analysis errors shows that forecast errors originate from analysis errors in the middle and upper troposphere. These errors rapidly expand in the vertical to span the troposphere, with a peak at the tropopause.
\end{abstract}

\section{Introduction}

A crucial factor that influences atmospheric predictability is error in the initial state, which we refer to here as analysis error. It is well known that these analysis errors amplify on the chaotic atmospheric attractor and that improving forecasts requires, in part, reducing analysis errors. However, little is known about analysis errors, despite the widespread acceptance of probabilistic approaches to prediction that admit this error, such as ensemble forecasting techniques that evolve multiple initial conditions. This is a troubling fact given that many interrelated predictability issues, such as ensemble forecasting, targeted observations, and data assimilation, all rest upon assumptions of analysis errors. This paper describes a study of estimates of analysis errors with an emphasis on their vertical structure and

Corresponding author address: Gregory J. Hakim, Department of Atmospheric Sciences, Box 351640, University of Washington, Seattle, WA 98195-1640.

E-mail: hakim@atmos.washington.edu evolution into forecast errors. In reality the true state is never known, and some approximation must be used to estimate the errors. Here a small ensemble of operational analyses is used to estimate the true state and errors; a discussion of this approximation is provided in section 2.

One motivation for limiting the scope of this project to the vertical structure of analysis and forecast errors is tractability. A second motivation is that the largest controversies related to analysis error involve the vertical profile. In particular, finite-time stability calculations of the optimal ("nonmodal") type, defined by nonseparable disturbance space and time structure, typically differ from synoptic experience and modal stability analyses. For example, singular-vector calculations that optimize disturbance total energy typically yield highly tilted structures in the lower and middle troposphere (e.g., Buizza and Palmer 1995; Palmer et al. 1998). The relevance of these structures depends on how well the total-energy norm approximates the analysis-error covariance norm (Ehrendorfer and Tribbia 1997). Evidence suggesting that the energy norm is consistent 
with the analysis-error covariance norm is limited to horizontal structure based on similarities between the Fourier spectra for singular vectors and small samples of analysis differences (Molteni et al. 1996; Palmer et al. 1998; Gelaro et al. 1998).

In contrast, synoptic experience (e.g., Petterssen and Smebye 1971; Hoskins et al. 1985) and modal stability calculations (e.g., Rotunno and Bao 1996; Hakim 2000a) emphasize the importance of tropopause undulations that produce potential vorticity anomalies having little or no vertical tilt (e.g., Hakim 2000b). It is plausible that analysis errors have a similar structure due to phase and amplitude errors of these primary features (Snyder 1999; Snyder and Hakim 2005). Resolving this controversy has implications beyond enhancing basic understanding of atmospheric dynamics. It also bears upon current and future efforts toward deploying supplemental observing systems, where the routine observing network is adaptively adjusted or systematically augmented to improve forecasts in specific locations. In the absence of complete knowledge of analysis errors it is unclear whether, on average, more observations are needed near the tropopause or in the lower to middle troposphere.

Although relatively little is known about analysis errors, considerable effort has been devoted to a closely related problem in state estimation. Data assimilation techniques, such as three- and four-dimensional variational schemes [three-dimensional variational data assimilation (3DVAR) and four-dimensional variational data assimilation (4DVAR)], require knowledge of a background field and its error statistics. Although the background field, typically a 6-h forecast, is constantly changing with time, its errors are usually assumed to have stationary statistics in the form of a fixed covariance matrix. Models of this covariance matrix are constructed by studying innovations, which represent the difference between observations and the background's estimate of these observations (e.g., Hollingsworth and Lönnberg 1986; Bartello and Mitchell 1992; Franke 1999; $\mathrm{Xu}$ and Wei 2001) and also from differences between forecasts verifying at the same time (e.g., Rabier et al. 1998; Derber and Bouttier 1999). The main result of these studies is a model that describes how different locations and different variables covary, so that observational information can be spatially spread to all model variables. Thus these covariance models are used primarily to determine analyses, not analysis errors. Estimates of analysis error can be obtained through the Hessian, which is the second derivative of the variational cost function with respect to the model state (Rabier and Courtier 1992; Barkmeijer et al. 1999). Hessian-based singular vectors peak at the tropopause, rather than in the lower troposphere as for the energy singular vectors (Barkmeijer et al. 1999). In a related, but distinct, approach Hamill et al. (2003) used an ensemble Kalman filter to estimate time- dependent analysis-error covariances in a simplified general circulation model. Their analysis-error covariance singular vectors also peak at the tropopause.

Other than case studies, research into forecast errors has primarily addressed predictability and error growth in terms of hemispheric or global metrics (e.g., Lorenz 1982; Dalcher and Kalnay 1987; Reynolds et al. 1994; Simmons and Hollingsworth 2002). Simmons and Hollingsworth (2002) also examined 500-hPa geopotential height analysis differences from the European Centre for Medium-Range Weather Forecasts and the Met Office. For the Northern Hemisphere, the results show that the analysis differences are largest over the North Pole, North Pacific, and North Atlantic regions. In a study of potential vorticity forecast errors, Dirren et al. (2003) found the most rapid growth in the 200-400-hPa layer, with an error doubling time of about $12 \mathrm{~h}$.

Our goal here is to estimate the dominant vertical structure of analysis and forecast errors using a small ensemble of operational analyses and forecasts. Specific attention is devoted to the midlatitude storm tracks by limiting the study to meridional wind and temperature at $40^{\circ} \mathrm{N}$. The data and method of analysis are described in section 2. Results for the vertical structure of analysis and forecast errors are shown in sections 3 and 4, respectively. Section 5 addresses the growth of errors at fixed vertical levels. The assumption of separable vertical and horizontal structure is relaxed in section 6, where error structure and propagation are analyzed using linear regression. A summary is provided in section 7 .

\section{Data and method}

The true state of the atmosphere is never precisely known, so some approximation is necessary to define analysis and forecast errors. Errors are defined here with respect to an ensemble mean of operational analyses; that is, the ensemble-mean analysis is taken to be the true state. This approximation is a generalization of the "analysis differences" method that is described along with other approximations of analysis errors in Daley and Mayer (1986). As discussed by Daley and Mayer, operational analyses are not completely independent because they use roughly comparable models, data assimilation schemes, and observations. Although, strictly speaking, the differences of ensemble-member analyses from the ensemble mean are not analysis errors, the term "analysis error" is used here to refer to these differences. We expect that forecast errors are affected less by this approximation, since they grow rapidly in time and, for lead times of $12 \mathrm{~h}$ or longer, are large compared to analysis errors (e.g., see Fig. 2).

At a particular grid point, the column vector of vertical structure for each ensemble-member analysis is denoted by $\mathbf{x}_{i}$ and the ensemble-mean analysis by $\overline{\mathbf{x}}=$ $n^{-1} \sum_{i=1}^{n} \mathbf{x}_{i}$, where $n$ is the number of ensemble mem- 
bers. Analysis errors, $\mathbf{x}_{i}^{e}$, are defined as the difference of individual ensemble members from this mean value,

$$
\mathbf{x}_{i}^{e}=\mathbf{x}_{i}-\overline{\mathbf{x}}
$$

Forecast errors are also defined relative to the ensemble-mean analysis,

$$
\mathbf{y}_{i}^{e}=\mathbf{y}_{i}-\overline{\mathbf{x}}
$$

where $\mathbf{y}_{i}$ is a column vector of vertical structure for an ensemble-member forecast, $\mathbf{y}_{i}^{e}$ is a column vector of forecast errors, and $\overline{\mathbf{x}}$ applies at the verifying time for the forecast.

Ensemble-member analyses and forecasts are taken from the National Centers for Environmental Prediction [NCEP; the Global Forecast System (GFS)], Met Office, Fleet Numerical Meteorology and Oceanography Center [the Navy Operational Global Atmospheric Prediction System (NOGAPS)], and the Canadian Meteorological Centre [CMC; Global Environmental Multiscale (GEM) model]. These data are made available to the University of Washington after transforming from native model grids to $1^{\circ}$ latitude-longitude grids ${ }^{1}$ on mandatory pressure levels from 1000 to $100 \mathrm{hPa}$ (excepting $925 \mathrm{hPa}$ ). Data for this study are taken from October to November 2003; a much longer sample of GFS and NOGAPS fields for 2000-03, with coarser vertical resolution, gives results qualitatively similar to those shown here. As stated earlier, the specific focus of this study is the midlatitude storm tracks, as captured in the meridional wind $(V)$ and temperature fields $(T)$ at $40^{\circ} \mathrm{N}$ latitude.

The dominant vertical structures of analysis and forecast errors are determined primarily from principal component analysis (e.g., Wilks 1995). For analysis errors, an $N \times M$ matrix, $\mathbf{X}^{e}$, is formed, where the $M$ columns represent samples of the vertical structure of analysis errors at $\mathrm{N}$ levels, $\mathbf{x}_{i}^{e}$; here, $\mathrm{N}$ is 10 . The exact number of samples depends on missing times, but most gridpoint (zonal wavenumber) fields have approximately 480 (280) samples. After removing the mean value at each level from $\mathbf{X}^{e}$, the $N \times N$ covariance matrix is computed as the outer product $\mathbf{C}=\mathbf{X}^{e} \mathbf{X}^{e \mathrm{~T}}$. Because $\mathbf{C}$ is Hermitian, its eigenvectors are orthogonal, and following meteorological convention will be referred to as empirical orthogonal functions (EOFs). For complex data, such as zonal wavenumber Fourier coefficients, the complex EOFs also give information about tilts in the vertical direction.

When divided by the total variance, the eigenvalue corresponding to an eigenvector measures the fraction of the total variance explained by that vertical structure. EOFs are computed for both specific locations and for zonal wavenumber 9, which together provide

\footnotetext{
${ }^{1}$ With the exception of $\mathrm{CMC}$, which is provided at $1.25^{\circ}$ resolution.
}

local and global measures of the vertical structure of errors, respectively. Zonal wavenumber 9 is chosen because it is broadly representative of baroclinic waves, and it approximates the horizontal scale that exhibits the largest error growth in $V$ forecast errors (e.g., Fig. 2a). A similar approach is taken for forecast errors by replacing $\mathbf{X}^{e}$ in the preceding discussion with $\mathbf{Y}^{e}$, which has columns given by the ensemble-member forecast errors, $\mathbf{y}_{i}^{e}$.

To place the forthcoming results for specific locations in context, Fig. 1 shows the root-mean-square (rms) values of both analysis and analysis-error fields for $\mathrm{V}$ and T. At each point the rms values are defined by $\left[\mathrm{m}^{-1}\right.$ $\left.\sum_{j=1}^{m} f_{j}^{2}\right]^{1 / 2}$, where $m$ gives the total number of fields and $f$ represents a $V$ or $T$ analysis or analysis-error field; the rms values are calculated after removing the time mean. The midlatitude storm tracks are apparent in Fig. $1 \mathrm{a}$ as a zonal band of large rms $\mathrm{V}$ values at $300 \mathrm{hPa}$, with peaks over the North Pacific and North Atlantic

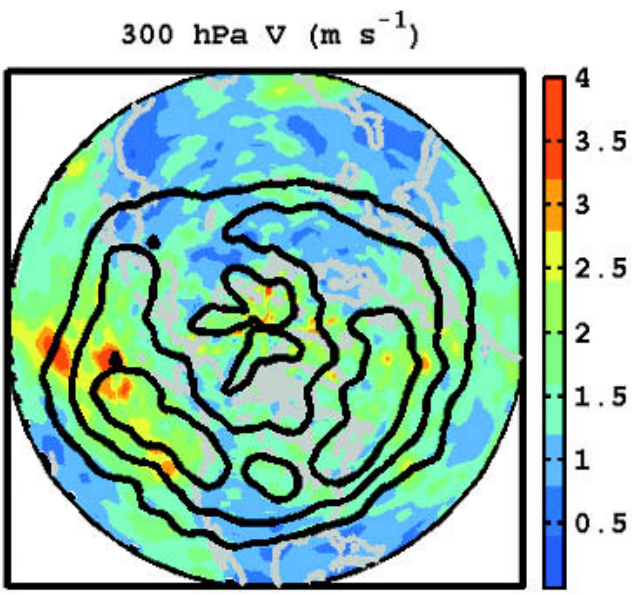

a

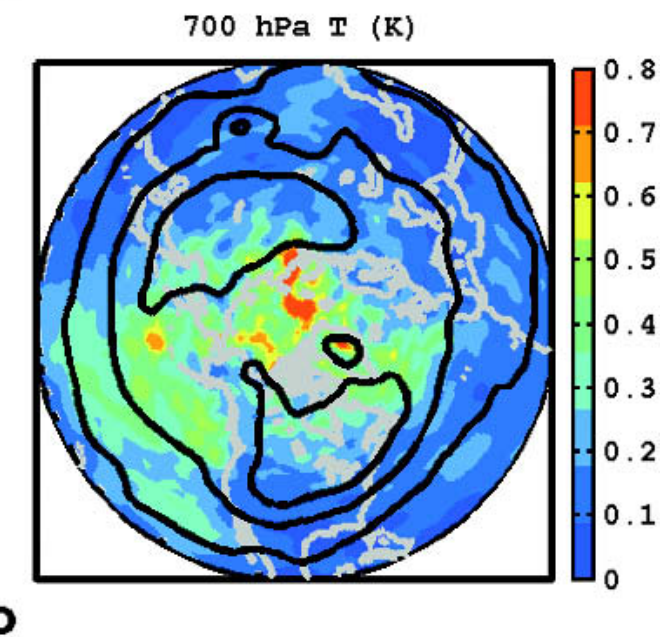

FIG. 1. Analysis rms fields (contours) and rms analysis errors (colors) for Oct-Nov 2003. (a) Meridional wind at $300 \mathrm{hPa}$ (contours: 12,16 , and $20 \mathrm{~m} \mathrm{~s}^{-1}$ ) and (b) $700-\mathrm{hPa}$ temperature (contours: 2,4 , and $6 \mathrm{~K}$ ). 
Oceans. Although the rms V analysis-error field is noisier than the analysis field, there is a fairly good correspondence between the two, with the largest errors concentrated toward the central and eastern portions of the Pacific and Atlantic Oceans, where observation density is low. In contrast, rms $T$ analysis values at $700 \mathrm{hPa}$ show local maxima over the continents, and largest rms $T$ analysis errors over the northern oceans and polar regions (Fig. 1b).

Figure 2 summarizes the growth of errors from analyses into forecasts as measured by Fourier amplitude spectra along $40^{\circ} \mathrm{N}$. Analysis errors for $\mathrm{V}$ appear on this plot to be white (i.e., independent of wavenumber) over planetary and synoptic scales; however, this is due to the logarithmic ordinate. There is a peak at zonal
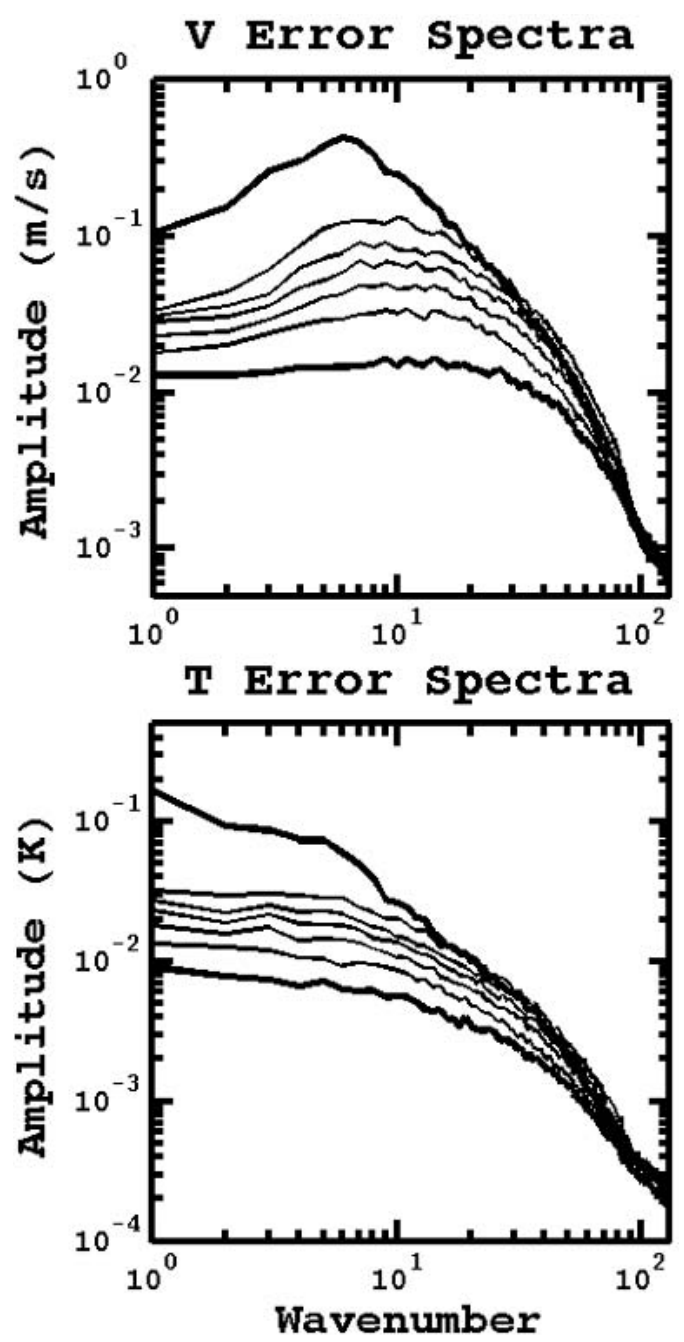

FIG. 2. Fourier amplitude spectra at $40^{\circ} \mathrm{N}$ for (top) $300-\mathrm{hPa}$ meridional wind and (bottom) 700-hPa temperature. The uppermost line represents analyses, and the lowermost line represents analysis errors. Thin lines denote forecast errors at $t=12,24,36$, 48 , and $72 \mathrm{~h}$, with increasing error amplitude for increasing forecast lead time. The spectra are averaged for the period Oct-Nov 2003. wavenumber 12 , and a decrease toward higher wavenumbers, which steepens where the analysis errors saturate and merge into the analysis spectrum (Fig. 2a). Forecast-error spectra for 12-, 24-, 36-, 48-, and 72-h lead times show that the greatest amplification in error amplitude occurs in the band dominated by baroclinic waves (zonal wavenumbers of $\sim 5-25$ ). There is a suggestion of the peak error moving upscale with increasing forecast lead time, and by $72 \mathrm{~h}$ the forecast-error spectrum is saturated above approximately zonal wavenumber 20 . In contrast, the $700-\mathrm{hPa} T$ analysis-error and forecast-error spectra are red (i.e., longwave dominated), and somewhat self-similar to the analysis spectrum (Fig. 2b).

\section{Vertical structure of analysis errors}

Analysis-error vertical structure EOFs at $40^{\circ} \mathrm{N}, 80^{\circ} \mathrm{W}$ and $40^{\circ} \mathrm{N}, 180^{\circ}$ for $V$ and $T$ are shown in Figs. 3 and 4 , respectively. These locations are chosen because they sample the downstream edge of a region with high observation density and relatively small analysis errors $\left(80^{\circ} \mathrm{W}\right)$ and a region of low observation density and relatively large analysis errors $\left(180^{\circ}\right)$; they are in fact broadly representative of most other longitudes at $40^{\circ} \mathrm{N}$. At both locations, the leading $V$ analysis-error EOF is sharply peaked at the tropopause, with little amplitude throughout the troposphere, except for a weak secondary maximum in the lower troposphere at $80^{\circ} \mathrm{W}$ (Fig. 3, thick lines). Leading analysis EOFs at

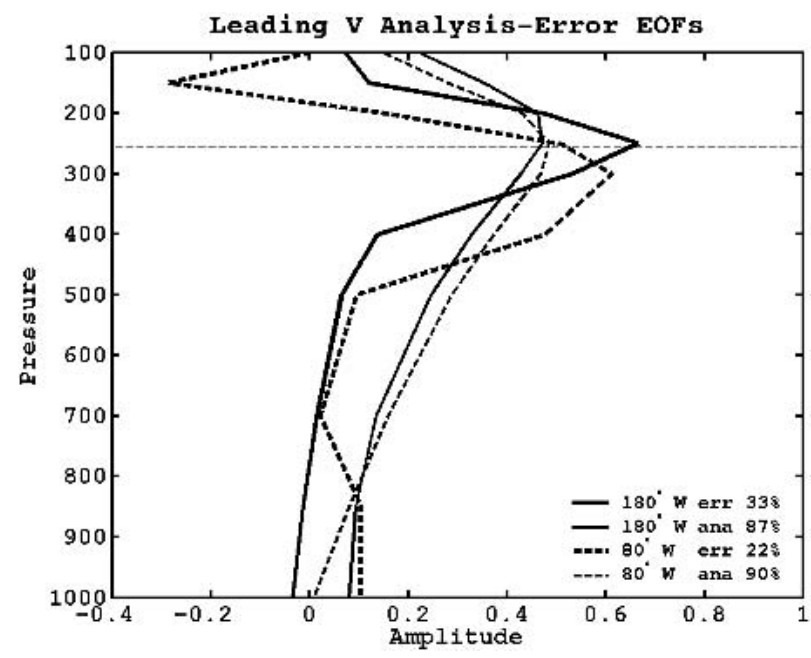

FIG. 3. Leading EOFs of the meridional wind for analysis error (thick lines) and analyses (thin lines) at $180^{\circ}$ (solid lines) and $80^{\circ} \mathrm{W}$ (dashed lines). Each EOF is normalized to have unit Euclidean norm. The thin horizontal solid (dashed) line depicts the mean dynamical tropopause at $180^{\circ}\left(80^{\circ} \mathrm{W}\right)$, where the dynamical tropopause is defined as the $1.5 \times 10^{-6} \mathrm{~m}^{2} \mathrm{~K} \mathrm{~kg}^{-1} \mathrm{~s}^{-1}$ Ertel potential vorticity surface. The numbers in the figure legend give the fraction of the total variance explained by each EOF; e.g., the leading analysis EOF at $80^{\circ} \mathrm{W}$ explains $90 \%$ of the variance in the vertical profile of the meridional wind at this location. 


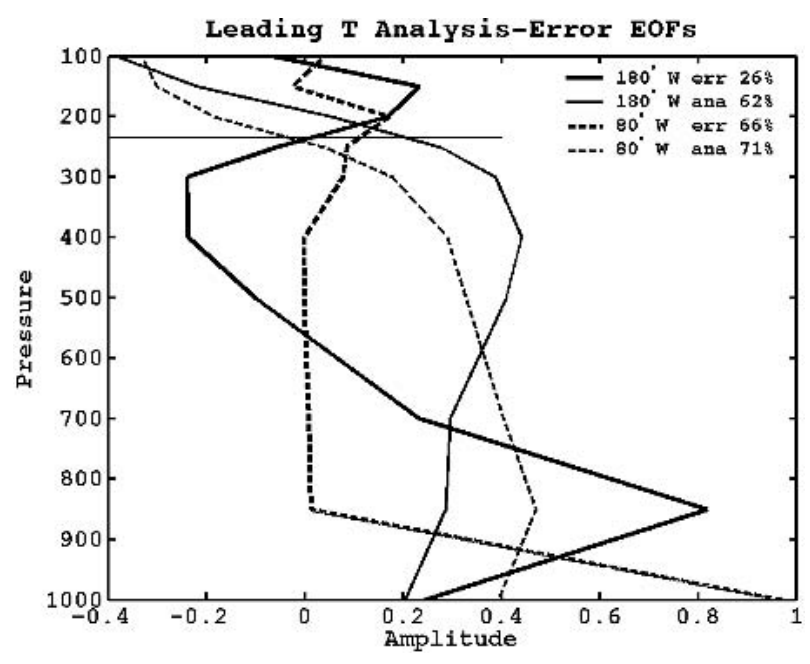

FIG. 4. As in Fig. 3, except for temperature.

these locations also peak at the tropopause, but are less sharply peaked, with nonzero amplitude extending to near the surface (Fig. 3, thin lines). It is interesting that the analysis EOFs peak right at the tropopause, whereas the analysis-error EOFs peak slightly below this level. This suggests the possibility of an asymmetry, with a bias for larger errors with downward deflections of the tropopause. These vertical profiles are qualitatively similar to vertical profiles of 6 -h forecast-error variance as estimated from innovations (e.g., Hollingsworth and Lönnberg 1986; Bartello and Mitchell 1992; $\mathrm{Xu}$ and Wei 2001) and forecast differences (e.g., Rabier et al. 1998).

Analysis-error EOFs for $\mathrm{T}$ are distinctly different from $\mathrm{V}$ in that their vertical structure is more complicated, and they differ substantially from analysis EOFs (Fig. 4). At $80^{\circ} \mathrm{W}$, the leading EOF is sharply peaked at $1000 \mathrm{hPa}$, with little amplitude above $850 \mathrm{hPa}$ in the troposphere. ${ }^{2}$ Conversely, the leading analysis EOF at $80^{\circ} \mathrm{W}$ exhibits a gradual decrease in the troposphere above a minor peak near $850 \mathrm{hPa}$ and an abrupt change in sign near the tropopause. This suggests that when the troposphere is anomalously warm (cold) the lower stratosphere is anomalously cold (warm), which along with the $\mathrm{V}$ results suggests an interpretation in terms of potential vorticity anomalies that result from variance in tropopause position. At $180^{\circ}$, the leading analysis EOF is similar, except with peak amplitude in the upper troposphere, which may reflect less variability in the lower troposphere due to thermal damping by the ocean surface. These results suggest that perhaps model error in the form of different boundary layer schemes may be important for the temperature analysis errors at $80^{\circ} \mathrm{W}$.

\footnotetext{
${ }^{2}$ Restricting the sample to the 0000 or 1200 UTC analyses yields the same EOFs, so apparently this result does not depend on the diurnal cycle.
}

Regarding the role of observation density, we note that the $300-\mathrm{hPa} V$ analysis-error variance at $180^{\circ}$ of 5.0 $\mathrm{m}^{2} \mathrm{~s}^{-2}$ compares with $1.7 \mathrm{~m}^{2} \mathrm{~s}^{-2}$ at $80^{\circ} \mathrm{W}$, and the sum of the variance at all vertical levels at these locations is 37 and $14 \mathrm{~m}^{2} \mathrm{~s}^{-2}$, respectively. Together with the leading EOF results, these values suggest that enhanced observation density reduces the magnitude of $V$ analysis errors, but does not significantly affect their vertical structure. For T, analysis-error variance is dominated by the boundary layer fields, particularly at $80^{\circ} \mathrm{W}$; analysis-error variance peaks at $1.2 \mathrm{~K}^{2}$ at $180^{\circ}(850 \mathrm{hPa})$ and $3.6 \mathrm{~K}^{2}$ at $80^{\circ} \mathrm{W}(1000 \mathrm{hPa})$. The sum of the variance at all levels is the same at both locations, but for the layer above $850 \mathrm{hPa}$, the total variance at $180^{\circ}$ of $3.9 \mathrm{~K}^{2}$ compares to $1.9 \mathrm{~K}^{2}$ at $80^{\circ} \mathrm{W}$. This shows that, above the boundary layer, $T$ analysis-error variance is also considerably smaller in the region of relatively higher observation density.

EOFs of zonal wavenumber 9 are determined by a similar procedure as for the gridpoint data, but for complex zonal Fourier coefficients of $V$ and $T$ fields along $40^{\circ} \mathrm{N}$ latitude at each vertical level. In addition to providing a "global" estimate of vertical structure near the midlatitude storm tracks, these EOFs also reveal the preferred vertical tilts. Results for the leading analysiserror EOFs of zonal wavenumber 9 are similar to the fixed locations discussed above (Figs. 5 and 6). The leading analysis-error $V$ EOF is sharply peaked slightly below the tropopause, with upshear tilt both above and below this location suggesting the possibility for growth of disturbance energy (Fig. 5). The analysis-error leading T EOF is confined below $700 \mathrm{hPa}$ and displays little tilt in the vertical (Fig. 6). Repeating the EOF analysis for analysis-error samples of $V$ and $T$ together (each sample column vector contains profiles for both $V$ and

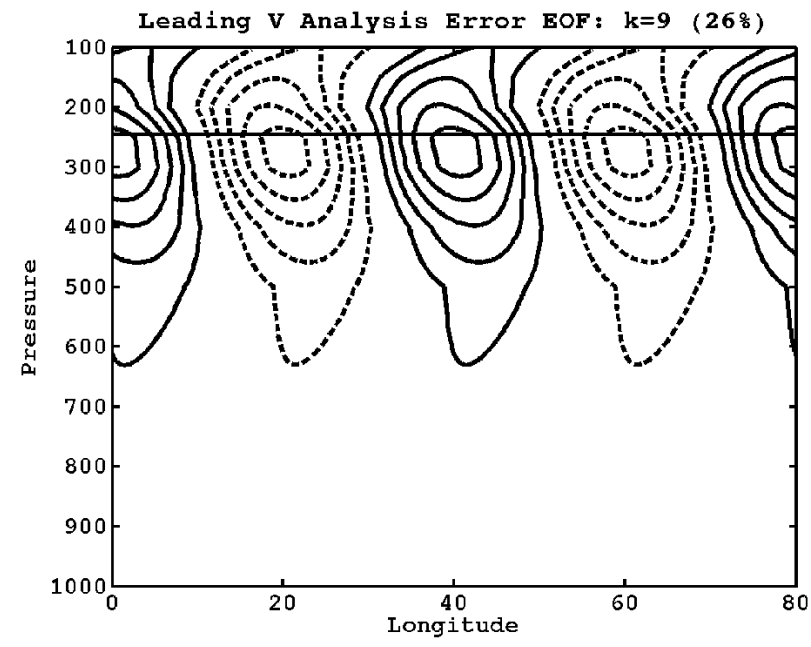

FIG. 5. Height-longitude section of the leading meridional-wind analysis-error EOF for zonal wavenumber 9 at $40^{\circ} \mathrm{N}$; only two wavelengths are shown. The EOF accounts for $26 \%$ of the total variance and is normalized to have unit Euclidean norm. The zero contour is suppressed, and the thin solid line is the tropopause. 
Leading $T$ Analysis Error EOF: $k=9$ (498)

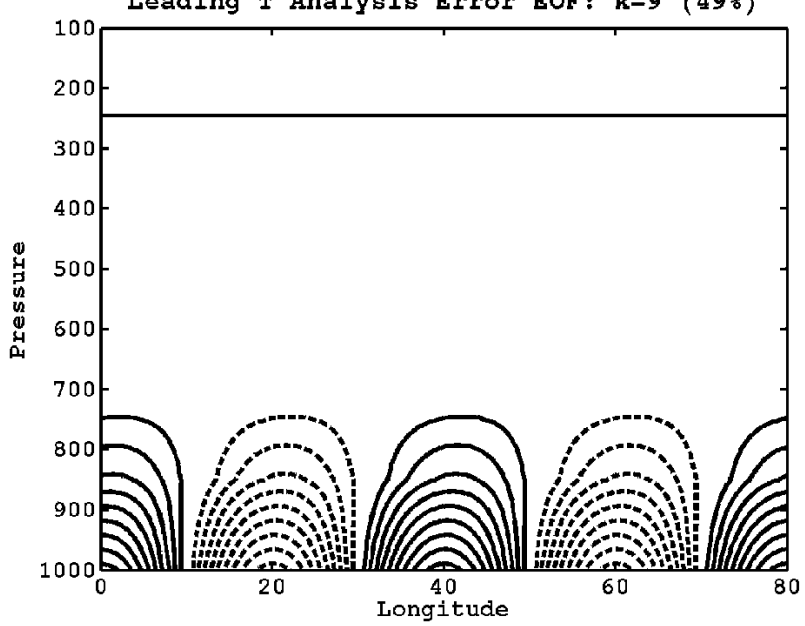

FIG. 6. As in Fig. 5, except for temperature.

$T)$ yields the same leading EOF for $V$ as in Fig. 5. Although the leading $T$ EOF has a surface-based peak as in Fig. 6, there is also a middle-tropospheric peak that appears to be in qualitative thermal-wind balance with the tropopause-based pattern in $V$ (not shown).

Analysis EOFs for $V$ and $T$ exhibit the classic structure of a growing baroclinic wave (Fig. 7). The leading $V$ EOF is peaked at the tropopause, decays rapidly into the stratosphere, and extends deeply through the troposphere with upshear tilt. The leading $T$ EOF shows deep temperature anomalies tilting with the tropospheric shear, and changing sign at the tropopause, consistent with PV anomalies due to undulations in this interface.

The results of this section suggest that the vertical
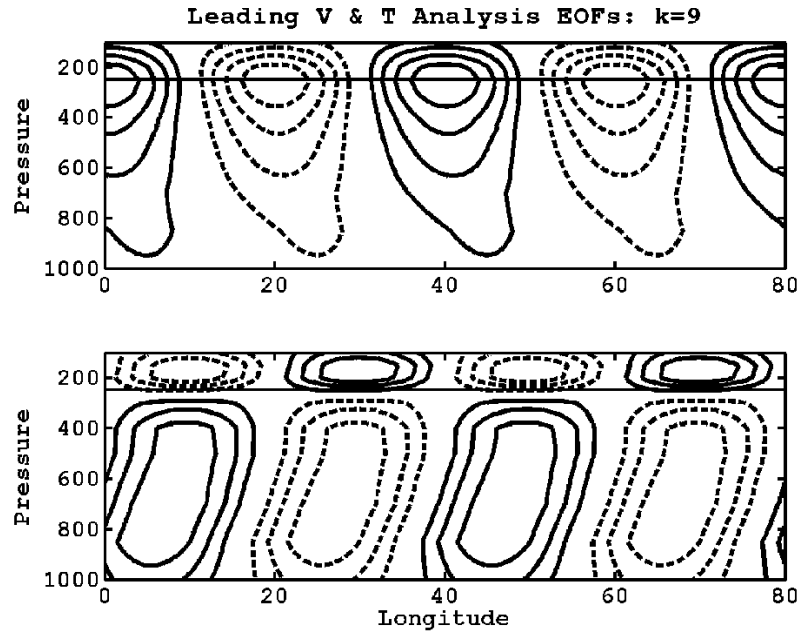

FIG. 7. Height-longitude section of the analysis EOFs for zonal wavenumber 9 at $40^{\circ} \mathrm{N}$ : (top) meridional wind and (bottom) temperature. Only two wavelengths are shown, and the thin solid line is the tropopause. structure of analysis errors for $V$ are similar to climatology, whereas $T$ errors are not. Since error fields should converge to climatological fields (i.e., analysis EOFs) as the errors develop in the forecast fields, we proceed to document that transition.

\section{Vertical structure of forecast errors}

Leading $V$ forecast-error EOFs for a range of forecast lead times are shown in Fig. 8. The vertical structure that dominates $V$ analysis errors rapidly converges to the vertical structure that dominates the analysis variance. It appears that the largest growth occurs in the first $12 \mathrm{~h}$, consistent with Fig. 2a. Note that "growth" is meant here to reflect the increase in variance in the dominant vertical structure, which may differ from the analysis errors that grow most rapidly; this issue will be addressed in sections 5 and 6 . Another noteworthy aspect of Fig. 8 is that the forecast EOFs appear to converge with a peak that is below the tropopause, whereas the analysis EOF peaks at the tropopause. As before, this result is interpreted as an indication that the models may be incapable of fully resolving the dynamics of downward fluctuations in the tropopause. Another interpretation is that downward tropopause deflections are associated with larger $\mathrm{V}$ than upward deflections. Although the bias (mean error) is small at $80^{\circ} \mathrm{W}$, at $180^{\circ}$ the vertical structure is similar to the leading EOF, with a positive bias of about $1.7 \mathrm{~m} \mathrm{~s}^{-1}$ at the tropopause by $48 \mathrm{~h}$ (not shown).

The evolution of $T$ forecast-error EOFs is more com-

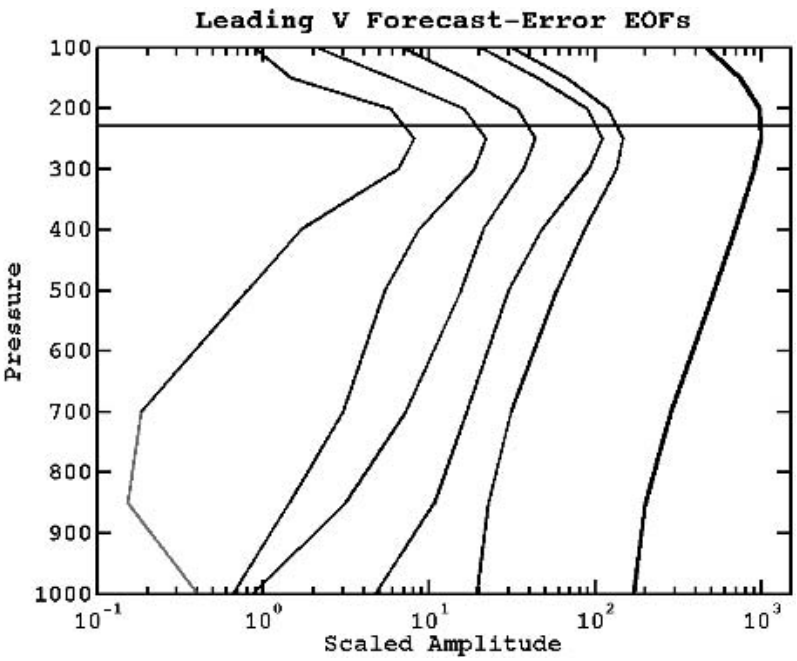

FIG. 8. Leading EOFs of the meridional wind for analyses, analysis errors, and forecast errors at $180^{\circ}$. Each EOF is scaled by its associated eigenvalue; i.e., by the variance associated with it. The analysis-error EOF is given by the leftmost line and the analysis EOF by the thick line. Other lines from left to right show forecast EOFs for lead times of 12, 24, 36, and $48 \mathrm{~h}$, respectively. Absolute values are plotted, with negative values distinguished by gray lines. The thin solid horizontal line is the tropopause. 
plicated than that for $V$ (Fig. 9). In particular, the analysis-error EOF differs substantially from the forecasterror EOFs at 12- and 24-h lead times. By $24 \mathrm{~h}$, the EOF is qualitatively similar to the analysis EOF. This change of structure is consistent with the strong middletroposphere growth in temperature errors to be shown in section 5 (see Fig. 11 later ). As with the $V$ forecast EOFs, the tropopause signal in the $T$ forecast EOFs is lower than in the analysis EOF. Mean forecast errors for $T$ indicate a cold bias in the lower troposphere at $80^{\circ} \mathrm{W}$, and a dipole near the tropopause at $180^{\circ}$, with a cold (warm) bias above (below) the tropopause (not shown).

Because the analysis, analysis-error, and forecasterror EOFs for $V$ all possess nearly the same structure, the changes in amplitude with forecast lead time are suggestive of error growth. The same interpretation does not apply as clearly to the $T$ EOFs.

\section{Error growth}

Having established the vertical structure of analysis and forecast errors, we now proceed to examine links between them; that is, the growth of analysis errors into forecast errors. Here we focus on the growth of errors at different levels for zonal wavenumber 9. This approach again assumes separable vertical and horizontal structure, but also that the errors remain at the same vertical level. These assumptions are relaxed in the subsequent section, where we consider vertical propagation and nonseparable spatial structure.

Error growth is defined here as

$$
\sigma=\frac{1}{|f|} \frac{d}{d t}|f|,
$$

where $|\cdot|$ represents a norm, which in keeping with our investigation of $T$ and $V$, is taken to be the modulus of

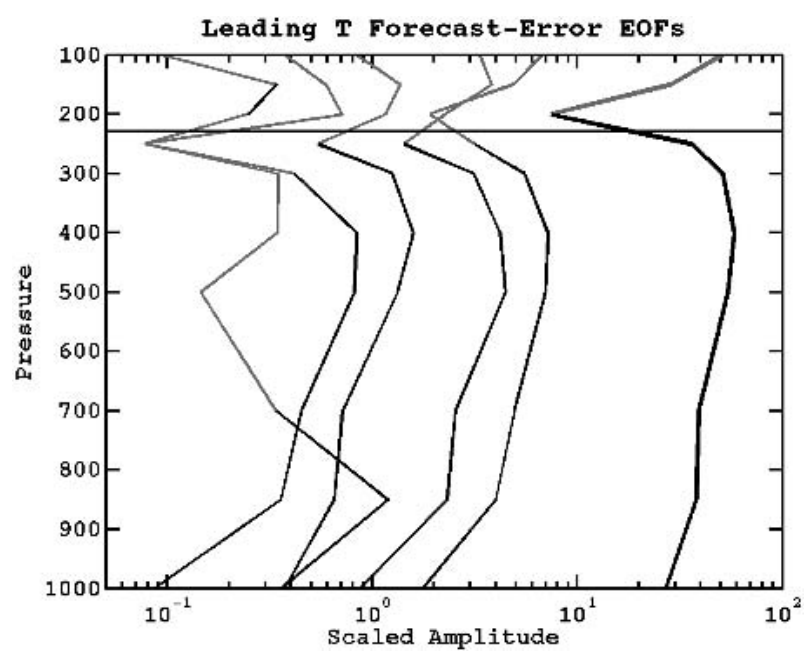

FIG. 9. As in Fig. 8, except for temperature. these quantities. Integrating (3) over a time interval from $t_{0}$ to $t$ we arrive at the expression that is evaluated numerically,

$$
\bar{\sigma}=\frac{1}{t-t_{0}} \ln \left(\frac{|f|_{t}}{|f|_{t_{0}}}\right),
$$

where $\bar{\sigma}$ represents the mean growth rate over the chosen time interval. For completeness, full probability density functions (PDFs) of error growth rates are considered for 700, 500, and $300 \mathrm{hPa}$.

At $700 \mathrm{hPa}$ the error $\mathrm{V}$ growth-rate PDF peaks at positive values, with tails toward larger, and also negative (decaying), values (Fig. 10). The error growthrate PDFs at 500 and $300 \mathrm{hPa}$ peak at even larger positive values, with mean $V$ error growth rates at $300 \mathrm{hPa}$ of 1.36 day $^{-1}$ or, equivalently, a doubling time of slightly more than $12 \mathrm{~h}$. This result is roughly half the value given by Simmons and Hollingsworth (2002), although their results are not directly comparable because the growth rates apply to $500-\mathrm{hPa}$ geopotential height over the entire Northern Hemisphere. Closer agreement is found with the results of Dirren et al. (2003), who found 12-h doubling times for potential vorticity forecast errors in the $200-400-\mathrm{hPa}$ layer.

Error-growth-rate PDFs for T show the peak of the PDFs for all levels slightly on the positive side of zero, with tails toward positive and negative growth rates (Fig. 11). The PDFs suggest that temperature errors have largest growth rates on average near $500 \mathrm{hPa}$, although the distribution tails show a bias for larger growth rates at 300 and $700 \mathrm{hPa}$. In fact, the mean error growth rates for 700,500 , and $300 \mathrm{hPa}$ are $0.67,0.66$, and $1.05 \mathrm{day}^{-1}$, respectively; at $300 \mathrm{hPa}$, the implied error doubling time is about $16 \mathrm{~h}$.

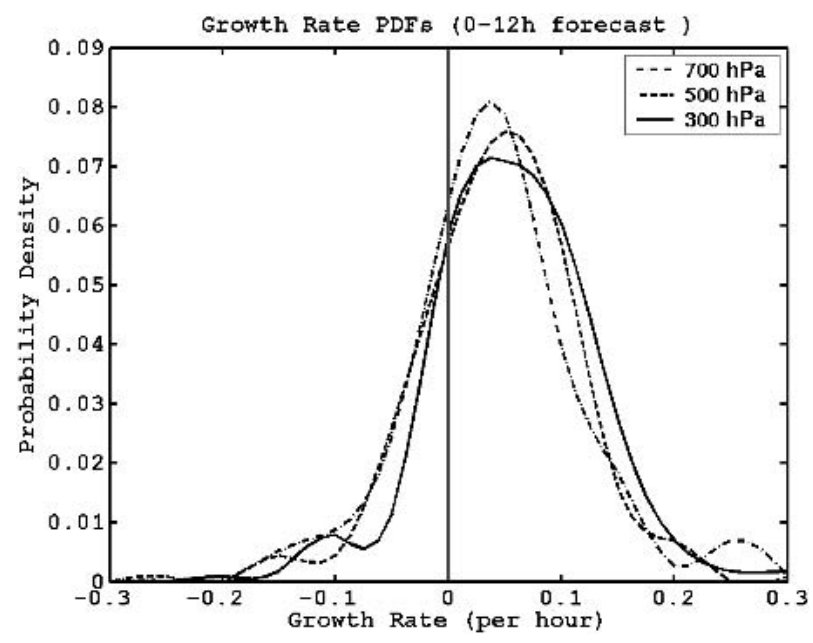

FIG. 10. Growth-rate probability density functions for zonalwavenumber-9 meridional wind. Growth rates apply to the $0-12-\mathrm{h}$ period at 700, 500, and $300 \mathrm{hPa}$. 


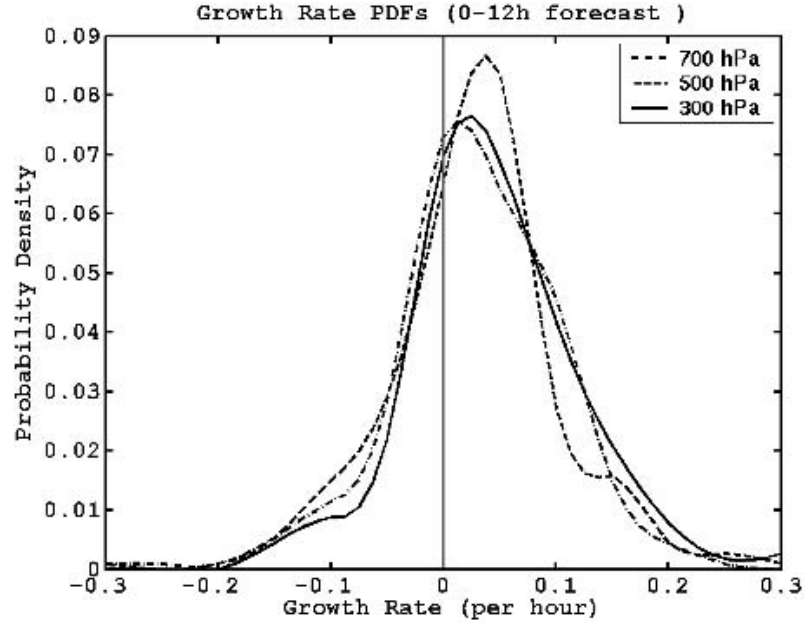

FIG. 11. As in Fig. 10, except for temperature.

\section{Error propagation and nonseparable spatial structure}

As discussed earlier, potentially important aspects of error growth may not be captured by the previous calculations due to nonseparable horizontal and vertical structure, and the vertical propagation of errors. These issues are briefly addressed here by three linear regression calculations. First, analysis and forecast $V$ errors at all points in the zonal cross section at $40^{\circ} \mathrm{N}$ are regressed onto a normalized sample of analysis errors at the reference point defined by $\left(150^{\circ} \mathrm{E}, 300 \mathrm{hPa}\right)$. The normalization is by the standard deviation at the reference point, which yields regression results in the units of $V$ (meters per second) [see Lim and Wallace (1991) for further details]. A second regression is performed on a normalized sample of analysis errors at the reference point $\left(150^{\circ} \mathrm{E}, 850 \mathrm{hPa}\right)$ to compare the evolution with the results for $300 \mathrm{hPa}$. Finally, a third regression is performed on a normalized sample of 24-h forecast errors at the reference point $\left(170^{\circ} \mathrm{W}, 300 \mathrm{hPa}\right)$ to determine the source region for errors that propagate to this location. These calculations are performed on a Fourier-filtered sample of errors, where only zonal wavenumbers 5-25 are retained, as suggested by Fig. $2 \mathrm{a}$, and the results are averaged for points within $\pm 5^{\circ}$ longitude of the reference point.

The regression results for analysis errors at $\left(150^{\circ} \mathrm{E}\right.$, $300 \mathrm{hPa}$ ) show that the signal is initially a sharply peaked wave packet that is concentrated near the tropopause (Fig. 12, top). These errors propagate eastward with time and develop deeper, baroclinic structure so that by $24 \mathrm{~h}$ the errors have begun to resemble a mature wave packet over the North Pacific Ocean (e.g., Chang and Yu 1999; Hakim 2003). An analysis of the error wave packet using the method of Hakim (2003) indicates that the dominant wavelength is approximately $3000 \mathrm{~km}$, or zonal wavenumber 10 , at $24 \mathrm{~h}$.

\section{$300 \mathrm{hPa}$ Analysis Error Propagation}

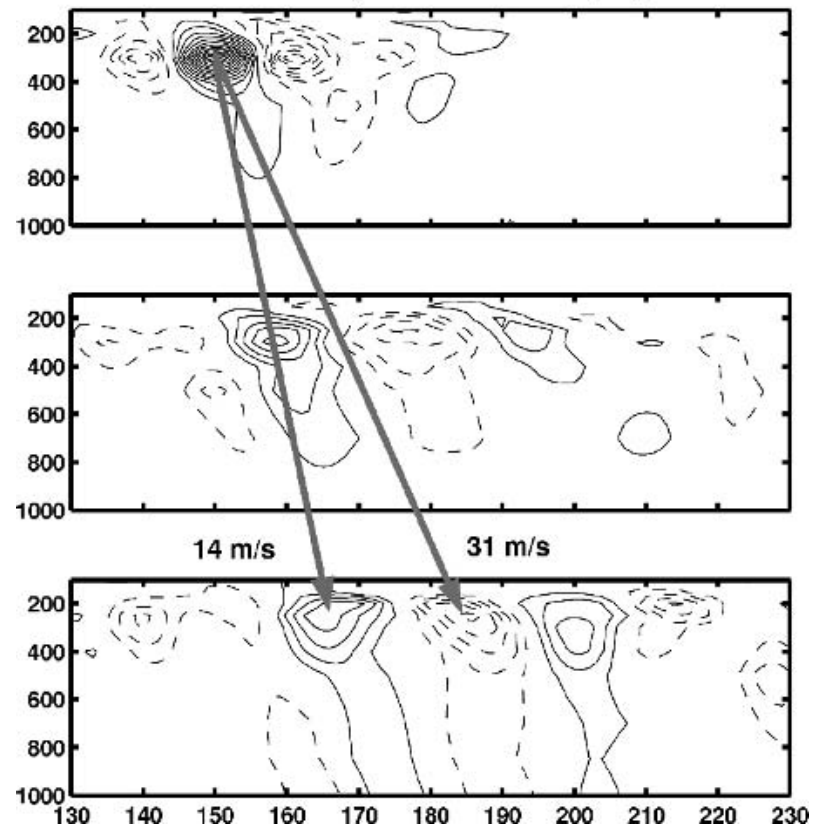

FIG. 12. Height-longitude section of error propagation across the North Pacific Ocean as determined by linear regression of meridional-wind errors on analysis errors at the point $\left(150^{\circ} \mathrm{E}, 300\right.$ $\mathrm{hPa}$ ): (top) analysis-error regression, (middle) 12-h forecast errors, and (bottom) 24-h forecast errors. Contour lines are every $0.1 \mathrm{~m} \mathrm{~s}^{-1}$, with negative values dashed; the zero contour is suppressed. Gray lines show estimates for the phase speed $\left(14 \mathrm{~m} \mathrm{~s}^{-1}\right)$ and group speed $\left(31 \mathrm{~m} \mathrm{~s}^{-1}\right)$.

This wavelength corresponds to the peak amplitude in the Fourier spectrum for initial and evolved singular vectors based on the analysis-error covariance metric of Barkmeijer et al. (1999). The phase speed of the errors is $14 \mathrm{~m} \mathrm{~s}^{-1}$ and the group speed of the packet peak ${ }^{3}$ is $31 \mathrm{~m} \mathrm{~s}^{-1}$; the mean zonal wind speed during the period of analysis is also $31 \mathrm{~m} \mathrm{~s}^{-1}$. This error group speed agrees well with the case studies of Szunyogh et al. (2002) who examined the propagation of analysis differences associated with dropsonde observations over the North Pacific.

The regression results for analysis errors at $\left(150^{\circ} \mathrm{E}\right.$, $850 \mathrm{hPa}$ ) show a concentration in the lower troposphere, although they extend weakly up to the tropopause, and there is little vertical tilt (Fig. 13a). These analysis errors propagate rapidly upward and downstream so that by $24 \mathrm{~h}$ they are concentrated near the tropopause, with little signature in the lower troposphere. Comparing regression amplitudes, the $850-\mathrm{hPa}$ errors have maximum absolute values of $0.9 \mathrm{~m} \mathrm{~s}^{-1}$ in the analysis and $0.3 \mathrm{~m} \mathrm{~s}^{-1}$ at $24 \mathrm{~h}$, whereas the corresponding values for $300-\mathrm{hPa}$ errors are $1.3 \mathrm{~m} \mathrm{~s}^{-1}$ in the analysis and $0.5 \mathrm{~m} \mathrm{~s}^{-1}$ at $24 \mathrm{~h}$.

\footnotetext{
${ }^{3}$ This location corresponds approximately with the point of maximum amplitude.
} 
$850 \mathrm{hPa}$ Analysis Error Propagation
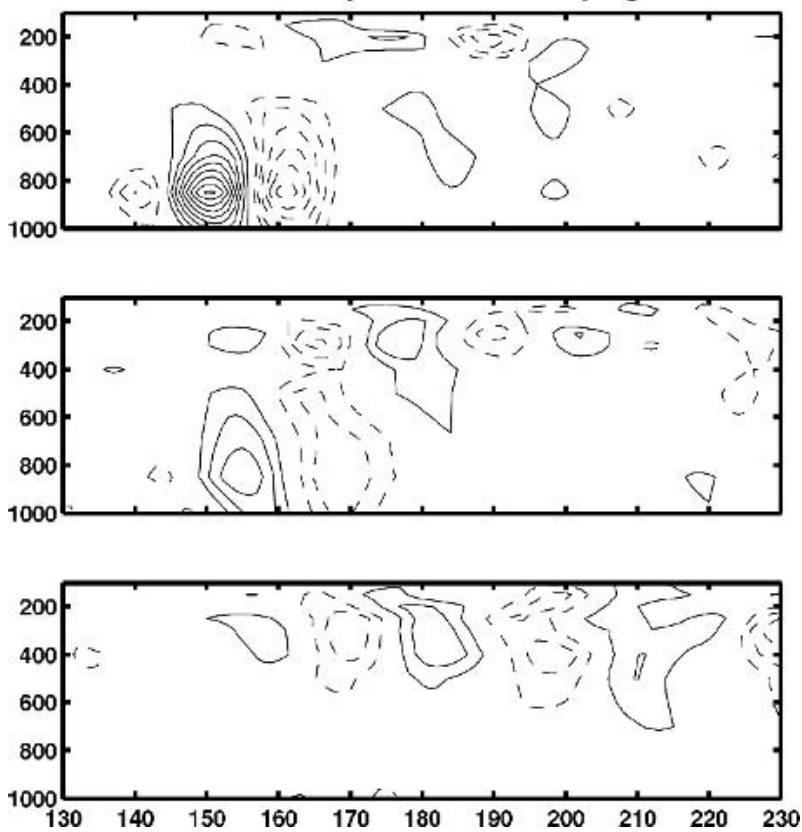

FIG. 13. As in Fig. 12, except for regression on analysis errors at $\left(150^{\circ} \mathrm{E}, 850 \mathrm{hPa}\right)$.

Figure 14 gives the results for the linear regression on 24-h forecast errors at $\left(170^{\circ} \mathrm{W}, 300 \mathrm{hPa}\right)$ to determine the error source location. The results show that these forecast errors are related to analysis errors that peak in the $400-500-\mathrm{hPa}$ layer near $150^{\circ} \mathrm{E}$, with a hint of a broader wave packet extending downstream. By $12 \mathrm{~h}$, these errors have amplified and extend in the vertical from a peak near the tropopause to the earth's surface. Maximum regression absolute values increase from $0.25 \mathrm{~m} \mathrm{~s}^{-1}$ in the analysis errors to $1.3 \mathrm{~m} \mathrm{~s}^{-1}$ in the $12-\mathrm{h}$ forecast errors and $4.1 \mathrm{~m} \mathrm{~s}^{-1}$ in the 24 -h forecast errors.

A potential link between the regression analysis and the EOF analyses presented earlier is provided by singular value decomposition (SVD) of the covariance matrix for analysis and forecast errors. Here we define the analysis-error-forecast-error covariance matrix for zonal wavenumber 9 by

$$
\mathbf{C}=\mathbf{X}^{\mathrm{e}} \mathbf{Y}^{\mathrm{eT}}
$$

where $\mathbf{X}^{\mathrm{e}}$ is the analysis-error matrix and $\mathbf{Y}^{\mathbf{e}}$ is the 12-h forecast-error matrix, as defined previously. Unlike the EOF analysis, each column sample of $\mathbf{X}^{\mathbf{e}}$ and $\mathbf{Y}^{\mathbf{e}}$ contains both $V$ and $T$ data, which allows determination of the relationship between these fields.

The SVD of $\mathbf{C}$,

$$
\mathbf{C}=\mathbf{U S ~ \mathbf { V } ^ { \mathrm { T } }},
$$

provides the analysis-error patterns (columns of $\mathbf{U}$ ) that optimally covary with forecast-error patterns (corresponding columns of $\mathbf{V}$ ). The diagonal matrix $\mathbf{S}$ con-
$300 \mathrm{hPa} 24 \mathrm{~h}$ Forecast Error Regression
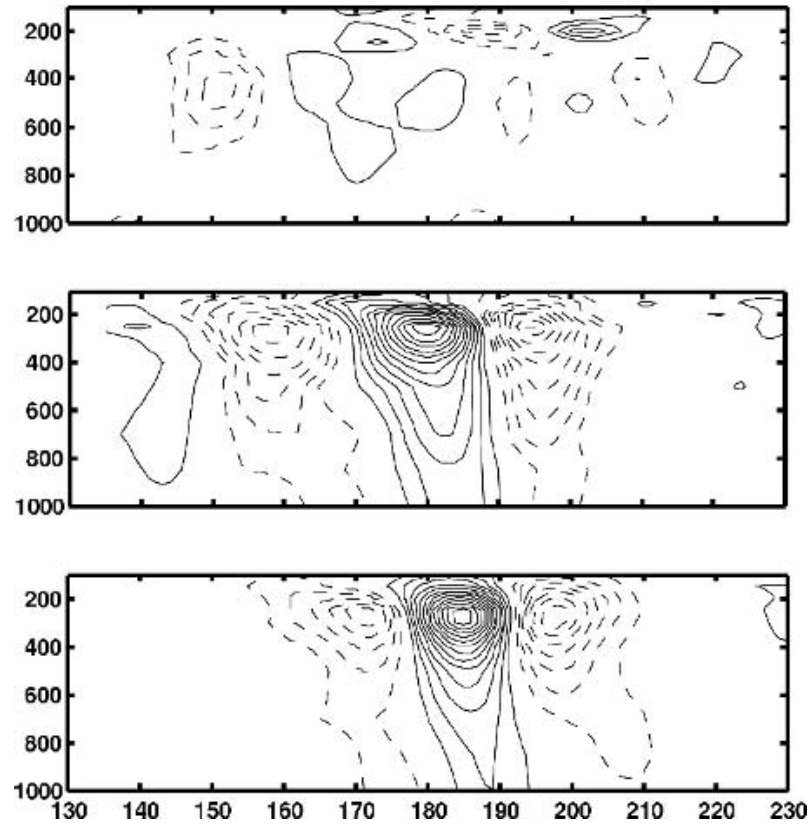

FIG. 14. As in Fig. 12, except for regression on 24-h forecast errors at $\left(170^{\circ} \mathrm{W}, 300 \mathrm{hPa}\right)$. Contour lines are shown every (top) $0.07 \mathrm{~m} \mathrm{~s}^{-1}$ for analysis errors, (middle) $0.1 \mathrm{~m} \mathrm{~s}^{-1}$ for $12-\mathrm{h}$ forecast errors, and (bottom) $0.3 \mathrm{~m} \mathrm{~s}^{-1}$ for 24 -h forecast errors.

tains the singular values that, when squared, define the fraction of the total analysis-error-forecast-error squared covariance accounted for by corresponding column pairs in $\mathbf{U}$ and $\mathbf{V}$ [Bretherton et al. 1992, their Eq. (15a)].

The leading covarying patterns, which account for $65 \%$ of the total squared covariance, are shown in Fig. 15 . The leading $\mathrm{V}$ analysis-error pattern is concentrated in the middle to upper troposphere and exhibits an upshear (westward) tilt with height (Fig. 15a), somewhat similar to the regression pattern in Fig. (14a); $T$ analysis errors have a peak at $850 \mathrm{hPa}$, with strong upshear tilt above this layer. The fact that the largest horizontal temperature gradients occur near 700-800 and 300-400 $\mathrm{hPa}$, which correspond to the locations of largest vertical gradient in $V$, suggests qualitative thermal-wind balance between these fields. The 12 -h forecast-error pattern that covaries with this analysis-error pattern exhibits a tropospheric-deep upshear tilt in $V$ with a sharp peak near the tropopause (Fig. 15b). The temperature pattern suggests that the largest relative growth occurs in the middle and upper troposphere, and a dipole near the tropopause suggests tropopause-based PV anomalies.

\section{Summary}

The dominant vertical structure of analysis and forecast errors are estimated using a small ensemble of op- 
(a)
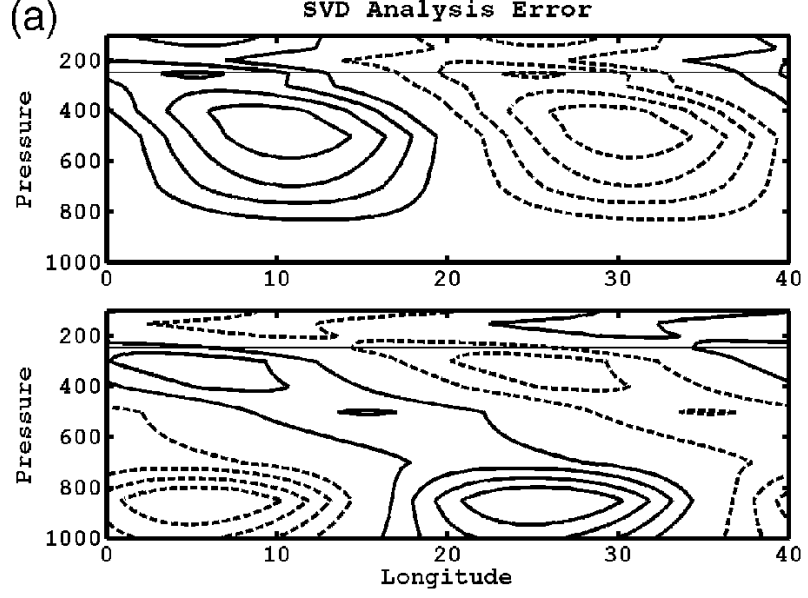

(b)
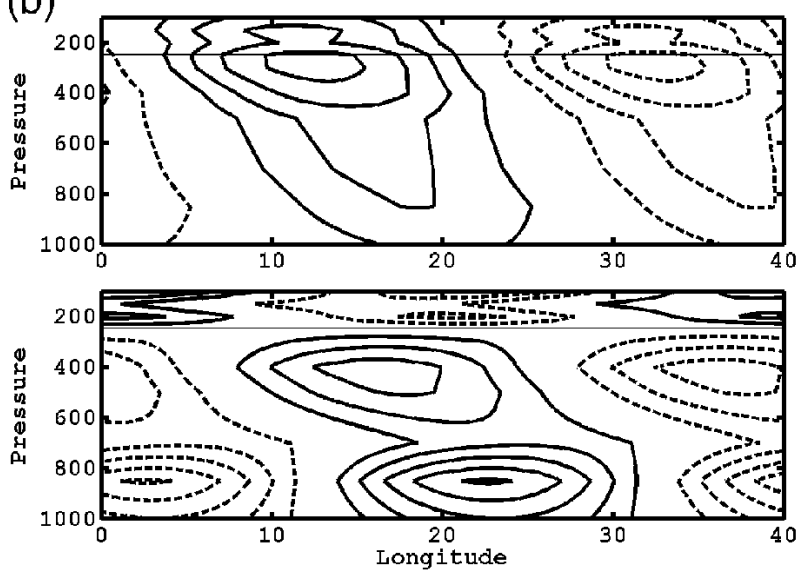

FIG. 15. Height-longitude section of the leading singular vectors of the covariance matrix for analysis errors and 12-h forecast errors for zonal wavenumber 9 at $40^{\circ} \mathrm{N}$. (a) The analysis-error patterns that covary with the forecast-error patterns in (b); these patterns account for $65 \%$ of the total squared covariance. In both (a) and (b), meridional wind is shown in the plot above temperature. Only one wavelength is shown. The thin solid horizontal line is the tropopause.

erational analyses. Primary emphasis is placed on midlatitudes and the growth of errors in the North Pacific storm track. Errors for fixed locations at $40^{\circ} \mathrm{N}$ in the central North Pacific $\left(180^{\circ}\right)$ and eastern North America $\left(80^{\circ} \mathrm{W}\right)$ are selected to compare errors in regions with low and high observation density, respectively. These fixed locations are also compared with results for zonal wavenumber 9, which lies in the range of baroclinic waves and is typical of a broader wave band. Results confirm that analysis-error variance is considerably smaller (by more than $50 \%$ ) in the region of higher observation density, although for temperature that is only true above the boundary layer; in the boundary layer, temperature analysis-error variance is found to be much larger over land (by nearly a factor of 3 ).

For meridional wind, which provides a simple and effective measure of baroclinic waves, the results indicate that errors near the tropopause account for the most variance. Leading vertical structures in analysiserror and forecast-error variance are very similar to the leading vertical structures in the analyses and climatology. ${ }^{4}$ Errors are largest near and below the tropopause and grow fastest in these locations as well. The fact that the errors peak just below the tropopause suggests an asymmetry in the error in the tropopause location with a bias toward greater errors for downward deflections. These downward deflections produce potential vorticity anomalies associated with baroclinic waves and coherent vortices that are responsible for much of the weather in midlatitudes.

While results for meridional-wind errors provide a clear and consistent picture, the same is not true for the dominant vertical structure in temperature errors. Leading analysis-error EOFs for temperature exhibit sharp peaks in the lower troposphere, with secondary features near the tropopause. This result differs substantially from the structure found for both forecast errors and analyses, which show a change in sign across the tropopause, consistent with undulations in the tropopause, and smooth vertical structure. One possible explanation is that the temperature analysis errors are particularly sensitive to boundary layer parameterization, and therefore are more strongly tied to the model.

Error growth rates at a given level are largest near the tropopause, with mean error doubling times of about $12 \mathrm{~h}$. To assess the role of error propagation and nonseparable spatial structure, linear regression is performed on a sample of errors located in the western North Pacific region. Analysis errors near the tropopause show a sharply peaked distribution that evolves into a deepening and spreading wave packet as it moves rapidly eastward. The dominant wavelength in the packet is about $3000 \mathrm{~km}$, or zonal wavenumber 10 , which is shorter than the typical $4000 \mathrm{~km}$ for stormtrack wave packets (e.g., Chang and Yu 1999; Hakim 2003). The peak of the error packet moves eastward at $31 \mathrm{~m} \mathrm{~s}^{-1}$, or about the speed of the mean zonal wind at the tropopause; the leading edge reaches western North America in just $24 \mathrm{~h}$. This group speed agrees with Szunyogh et al. (2002), who analyzed the propagation speed of analysis differences due to targeted dropsonde observations over the North Pacific in midwinter. Linear regression on analysis errors at $850 \mathrm{hPa}$ show a weaker signal with strong vertical propagation to the tropopause by $24 \mathrm{~h}$. A separate, consistent result is that 24-h forecast errors near the tropopause are found to originate in middle- and upper-tropospheric analysis er-

\footnotetext{
${ }^{4}$ Leading EOFs for the NCEP-National Center for Atmospheric Research reanalysis dataset yield the same vertical structure as the operational analysis used here (not shown).
} 
rors. Moreover, a singular value decomposition of analysis-error-forecast-error covariance for zonal wavenumber 9 at $40^{\circ} \mathrm{N}$ also shows that analysis errors in the 400-500-hPa layer, and the lower troposphere, covary strongly with 12 -h forecast errors that peak near the tropopause (Fig. 15).

We close with some comments regarding implications of these results for predictability issues including analysis perturbations for ensemble forecasting and supplemental observations for the current observing network. Regarding ensemble analysis perturbations, it has been shown that total-energy singular vectors typically peak in the lower troposphere with highly tilted vertical structure (e.g., Palmer et al. 1998). Results shown here are inconclusive with regard to the relevance of these structures. There is ample evidence, particularly for the $V$ field, that analysis errors are largest, and grow fastest, near the tropopause. There is also evidence, mainly from the temperature field, that tilted analysis-error structures in the middle and lower troposphere also contribute to forecast errors. Future work, perhaps using conditional sampling, will be required to make more definitive conclusions.

Regarding the observing network, the results suggest the need for additional observations in the middle and upper troposphere, particularly near and just below the tropopause; similarly, they imply a need for greater model resolution in this location to better capture downward deflections of the interface. These conclusions are contingent on the representativeness of the small analysis ensemble used here, although similar results are obtained when the ensemble is reduced to as few as two members. Tests of the robustness of these results will require future research with larger ensembles, such as operational implementation of ensemble Kalman filters.

Acknowledgments. I thank Dr. Chris Snyder (NCAR) for suggesting the complex EOF analysis for the vertical structure of zonal wavenumber 9 and for reviewing an earlier draft of the paper, and Prof. Clifford Mass (University of Washington) for providing access to the data. Manuscript reviews from Dr. Craig Bishop and an anonymous referee helped clarify aspects of the presentation. This research was sponsored by the National Science Foundation through NSF Grants ATM-9980744, ITR-0205648, ATM-0228804, and NOAA CSTAR Grant NA17RJ1232.

\section{REFERENCES}

Barkmeijer, J., R. Buizza, and T. N. Palmer, 1999: 3D-VAR Hessian singular vectors and their potential use in the ECMWF ensemble prediction system. Quart. J. Roy. Meteor. Soc., 125, 2333-2351.

Bartello, P., and H. L. Mitchell, 1992: A continuous threedimensional model of short-range forecast error covariances. Tellus, 44A, 217-235.

Bretherton, C. S., C. Smith, and J. M. Wallace, 1992: An inter- comparison of methods for finding coupled patterns in climate data. J. Climate, 5, 541-560.

Buizza, R., and T. N. Palmer, 1995: The singular-vector structure of the atmospheric global circulation. J. Atmos. Sci., 52, 14341456.

Chang, E. K. M., and D. B. Yu, 1999: Characteristics of wave packets in the upper troposphere. Part I: Northern Hemisphere winter. J. Atmos. Sci., 56, 1708-1728.

Dalcher, A., and E. Kalnay, 1987: Error growth and predictability in operational ECMWF forecasts. Tellus, 39A, 474-491.

Daley, R., and T. Mayer, 1986: Estimates of global analysis error from the global weather experiment observational network. Mon. Wea. Rev., 114, 1642-1653.

Derber, J., and F. Bouttier, 1999: A reformulation of the background error covariance in the ECMWF global data assimilation system. Tellus, 51A, 195-221.

Dirren, S., M. Didone, and H. C. Davies, 2003: Diagnosis of "forecast-analysis" differences of a weather prediction system. Geophys. Res. Lett., 30, 2060, doi:10.1029/2003GL017986.

Ehrendorfer, M., and J. J. Tribbia, 1997: Optimal prediction of forecast error covariances through singular vectors. J. Atmos. Sci., 54, 286-313.

Franke, R., 1999: Three-dimensional covariance functions for NOGAPS data. Mon. Wea. Rev., 127, 2293-2308.

Gelaro, R., R. Buizza, T. N. Palmer, and E. Klinker, 1998: Sensitivity analysis of forecast errors and the construction of optimal perturbations using singular vectors. J. Atmos. Sci., 55, $1012-1037$.

Hakim, G. J., 2000a: Role of nonmodal growth and nonlinearity in cyclogenesis initial-value problems. J. Atmos. Sci., 57, 29512967.

, 2000b: Climatology of coherent structures on the extratropical tropopause. Mon. Wea. Rev., 128, 385-406.

, 2003: Developing wave packets in the North Pacific storm track. Mon. Wea. Rev., 131, 2824-2837.

Hamill, T. M., C. Snyder, and J. S. Whitaker, 2003: Ensemble forecasts and the properties of flow-dependent analysis-error covariance singular vectors. Mon. Wea. Rev., 131, 1741-1758.

Hollingsworth, A., and P. Lönnberg, 1986: The statistical structure of short-range forecast errors as determined from radiosonde data. Part I: The wind field. Tellus, 38A, 111-136.

Hoskins, B. J., M. E. McIntyre, and A. W. Robertson, 1985: On the use and significance of isentropic potential vorticity maps. Quart. J. Roy. Meteor. Soc., 111, 877-946.

Lim, G. H., and J. M. Wallace, 1991: Structure and evolution of baroclinic waves as inferred from regression analysis. J. Atmos. Sci., 48, 1718-1732.

Lorenz, E. N., 1982: Atmospheric predictability experiments with a large numerical model. Tellus, 34, 505-513.

Molteni, F., R. Buizza, T. N. Palmer, and T. Petroliagis, 1996: The ECMWF ensemble prediction system: Methodology and validation. Quart. J. Roy. Meteor. Soc., 122, 73-119.

Palmer, T. N., R. Gelaro, J. Barkmeijer, and R. Buizza, 1998: Singular vectors, metrics, and adaptive observations. J. Atmos. Sci., 55, 633-653.

Petterssen, S., and S. J. Smebye, 1971: On the development of extratropical cyclones. Quart. J. Roy. Meteor. Soc., 97, 457482.

Rabier, F., and P. Courtier, 1992: Four-dimensional assimilation in the presence of baroclinic instability. Quart. J. Roy. Meteor. Soc., 118, 649-672.

— A. McNally, E. Andersson, P. Courtier, P. Undén, J. Eyre, A. Hollingsworth, and F. Bouttier, 1998: The ECMWF implementation of three-dimensional variational assimilation (3DVAR). II: Structure functions. Quart. J. Roy. Meteor. Soc., 124, 1809-1829.

Reynolds, C. A., P. J. Webster, and E. Kalnay, 1994: Random error growth in NMC's global forecasts. Mon. Wea. Rev., 122, 1281-1305.

Rotunno, R., and J.-W. Bao, 1996: A case study of cyclogenesis 
using a model hierarchy. Mon. Wea. Rev., 124, 1051-1067.

Simmons, A. J., and A. Hollingsworth, 2002: Some aspects of the improvement in skill of numerical weather prediction. Quart. J. Roy. Meteor. Soc., 128, 647-677.

Snyder, C., 1999: Error growth in flows with finite-amplitude waves or coherent structures. J. Atmos. Sci., 56, 500-506. , and G. J. Hakim, 2005: Cyclogenetic perturbations and analysis errors decomposed into singular vectors. J. Atmos. Sci., in press.
Szunyogh, I., Z. Toth, A. V. Zimin, S. J. Majumdar, and A. Persson, 2002: Propagation of the effect of targeted observations: The 2000 winter storm reconnaissance program. Mon. Wea. Rev., 130, 1144-1165.

Wilks, D. S., 1995: Statistical Methods in the Atmospheric Sciences. Academic Press, $464 \mathrm{pp}$.

Xu, Q., and L. Wei, 2001: Estimation of three-dimensional error covariances. Part II: Analysis of wind innovation vectors. Mon. Wea. Rev., 129, 2939-2954. 